\title{
Bolus administration of ephedrine and etilefrine induces transient vasodilation just after injection in combined epidural and general anesthesia patients: A randomized clinical study
}

\author{
Zen'ichiro Wajima ${ }^{1, *}$, Toshiya Shiga ${ }^{2}$, Kazuyuki Imanaga ${ }^{3}$ \\ ${ }^{1}$ Department of Anesthesiology, Tokyo Medical University Hachioji Medical Center, Tokyo, Japan; \\ ${ }^{2}$ Department of Anesthesiology and Intensive Care Medicine, International University of Health and Welfare, School of Medicine, \\ Narita, Chiba, Japan; \\ ${ }^{3}$ Department of Anesthesia, Shonan Kamakura General Hospital, Kamakura, Kanagawa, Japan.
}

\begin{abstract}
Summary Hypotension commonly accompanies combined epidural and general anesthesia, and intravenous bolus ephedrine and etilefrine are widely used to correct hypotension. We have noticed that systemic vascular resistance (SVR) transiently decreases just after intravenous bolus administration of these drugs. The goal of the present study was to investigate whether bolus administration of these drugs decrease SVR just after intravenous administration in combined epidural and general anesthesia patients. We investigated 40 patients who were scheduled for elective abdominal surgery. Patients were chosen as subjects if their systolic arterial pressure decreased by $20 \%$ or to $<100 \mathrm{mmHg}$ at $30 \mathrm{~min}$ after the induction of general anesthesia. Baseline hemodynamic values were recorded, and after ephedrine $10 \mathrm{mg}$ injection or etilefrine $2 \mathrm{mg}$ injection (equipotent), the parameters were recorded again at $0.5 \mathrm{~min}$ and once each $\mathrm{min}$ for the next $5 \mathrm{~min}$ thereafter. The 40 patients were enrolled into the ephedrine $(n=20)$ or etilefrine $(n=20)$ treatment groups. Patient characteristics were comparable in both groups. After ephedrine injection, SVR decreased significantly at the 1-min time point, whereas after etilefrine injection, SVR decreased significantly at the 0.5to 2-min time points compared with baseline values. SVR at the 0.5- to 1-min time points was lower in the etilefrine versus the ephedrine group. Both drugs transiently decreased SVR after intravenous injection, but etilefrine decreased SVR much more than ephedrine, indicating that more vasodilation occurred after the injection of etilefrine than after ephedrine. It is thus important to recognize the different characteristics of these drugs.
\end{abstract}

Keywords: Ephedrine, etilefrine, hemodynamics, systemic vascular resistance, vasodilation

\section{Introduction}

Hypotension commonly accompanies anesthesia (1), especially combined epidural and general anesthesia (2) which is a common anesthesia method, and intravenous (IV) ephedrine or etilefrine are widely used to resolve

Released online in J-STAGE as advance publication August 10, 2018.

*Address correspondence to:

Prof. Zen'ichiro Wajima, Department of Anesthesiology,

Tokyo Medical University Hachioji Medical Center, 1163

Tate-machi, Hachioji, Tokyo 193-0998, Japan.

E-mail: HFB01245@nifty.com such hypotension (2-9). We have noticed that these drugs transiently decrease systemic vascular resistance (SVR) just after bolus IV administration in combined epidural and general anesthesia patients prior to this study. To our knowledge, however, no reports have compared the very acute hemodynamic changes between ephedrine and etilefrine including those of SVR.

Therefore, in this randomized clinical study, we investigated whether the bolus administration of these drugs decreases SVR just after IV administration and also evaluated any potential differences in the very acute hemodynamics between IV ephedrine and etilefrine in combined epidural and general anesthesia patients, which have not been reported to date. 


\section{Materials and Methods}

\subsection{Study subjects}

We conducted a prospective, randomized, doubleblind study at the International University of Health and Welfare Shioya Hospital, Tochigi, Japan. The local hospital ethics committee approved the study protocol (protocol number 13-B-17, 2013-10-4), and the study was registered in the UMIN Clinical Trial Registry (ID: UMIN000011970). The Consolidated Standards of Reporting Trials (CONSORT) guidelines were followed. Written informed consent was obtained from all subjects. Female and male patients aged 20-75 years of American Society of Anesthesiologists' (ASA) physical classes I to II were eligible for inclusion if scheduled to undergo upper or lower abdominal surgery requiring combined epidural and general anesthesia. Patients with known diabetes mellitus, diseases of the cardiovascular (including arrhythmia), pulmonary, neurologic, endocrinologic, or autonomic systems, and diseases affecting intravascular fluid volume or balance, e.g., inflammatory diseases or obstructive diseases of the gastrointestinal tract, were excluded. Furthermore, we did not administer either ephedrine or etilefrine in tachycardic patients $(H R>100)$ because we believe that these drugs should not be administered to such patients. All patients fasted preoperatively for at least 8 hours, and none of the patients received any premedication.

\subsection{Anesthesia technique}

Before the induction of general anesthesia, an epidural catheter was inserted cephaladly to a distance of $4 \mathrm{~cm}$ within one intervertebral space (Th8-9 to Th11-12). We use the loss-of-resistance technique with physiological saline to identify the epidural space $(10,11)$. Anesthesia of $1 \%$ epidural lidocaine $(6-12 \mathrm{~mL})$ was administered, and the level of analgesia was tested with a pinprick 15 min after the epidural lidocaine was administered. We confirmed that the cephalad analgesia level was at least Th5 and the lower (caudad) analgesia level was at least L1.

General anesthesia was induced with IV administration of propofol at an initial effect-site concentration of $4 \mu \mathrm{g} / \mathrm{mL}$ and remifentanil $1 \mu \mathrm{g} /$ $\mathrm{kg}$ in total, along with rocuronium $0.6 \mathrm{mg} / \mathrm{kg} \mathrm{IV}$. Thereafter, we inserted a 23-gauge catheter into either the left or right radial artery to directly monitor arterial pressure. We used a semi-closed circle system to mechanically ventilate the patients' lungs at a fresh gas flow of $6 \mathrm{~L} / \mathrm{min}\left(\mathrm{O}_{2}, 2 \mathrm{~L} / \mathrm{min}\right.$ and air, $\left.4 \mathrm{~L} / \mathrm{min}\right)$. The controlled ventilation rate was 10 breaths/min at an inspiratory:expiratory ratio of $1: 2$, and a tidal volume of $8 \mathrm{ml} / \mathrm{kg}$ was used. The effect-site concentration of the propofol (administered by plasma target-controlled infusion) was later adjusted to maintain a target BIS of
40 to 60 and stable circulatory variables.

\subsection{Monitoring equipment}

We continuously monitored the systolic arterial pressure (SAP), mean arterial pressure (MAP), diastolic arterial pressure (DAP), heart rate (HR), pressure of endtidal $\mathrm{CO}_{2}\left(\mathrm{P}_{\mathrm{ET}} \mathrm{CO}_{2}\right), \mathrm{SVV}$, cardiac output $(\mathrm{CO})$, stroke volume index (SVI), and SVR with a CARESCAPE B850 monitor (GE Healthcare, Helsinki, Finland) and a FloTrac/Vigileo ${ }^{\mathrm{TM}}$ system (software ver. 03.06; Edwards Lifesciences, Irvine, CA, USA). We did not use a central venous catheter to directly measure the patient's central venous pressure (CVP). Instead, the SVR data was obtained using a fixed CVP of $0 \mathrm{mmHg}$ by inputting this pressure value into the FloTrac/ Vigileo $^{\mathrm{TM}}(12,13)$.

Each patient became a subject if at 30 min after induction of general anesthesia, the systolic blood pressure had decreased by $>20 \%$ compared with that just before epidural anesthesia or had dropped to $<100$ $\mathrm{mmHg}$. However, if either severe hypotension (mean blood pressure $<50 \mathrm{mmHg}$ ) or no hypotension at all occurred, the patient was excluded as a subject (Figure 1). Furthermore, we did not administer either ephedrine or etilefrine in tachycardic patients $(H R>100)$ because we believe that these drugs should not be administered to such patients. Each chosen patient was randomized to receive ephedrine or etilefrine by a computer-generated list using an allocation ratio of 1:1. The baseline values of the hemodynamic parameters and those of SAP, MAP, DAP, HR, $\mathrm{P}_{\mathrm{ET}} \mathrm{CO}_{2}, \mathrm{SVV}, \mathrm{CO}, \mathrm{SVI}$, and SVR of the patients were recorded. Then, the patients were administered either ephedrine $10 \mathrm{mg}$ or etilefrine $2 \mathrm{mg}$ (the doses are equipotent $(8,14)$ ) that was prepared in identically coded syringes by a nurse not involved in the study. Because the pressure waveform is sampled by the Vigileo ${ }^{\mathrm{TM}}$ at $100 \mathrm{~Hz}$ over $20 \mathrm{~s}$ and it provides calculations at the end of each 20 -s timeframe, the values of SVV, CO, SVI, and SVR were recorded $20 \mathrm{~s}$ after recording of the SAP, MAP, DAP, HR, and $\mathrm{P}_{\mathrm{ET}} \mathrm{CO}_{2}$ (15). These values were recorded again at $0.5 \mathrm{~min}$ after the ephedrine or etilefrine IV administration and every $1 \mathrm{~min}$ for 5 min thereafter. Assessments of the recorded values were performed by a blinded assessor. We conducted all studies before the surgery began, and we administered just $100 \mathrm{~mL}$ of normal saline to the patients to ensure minimal change in SVV values during the induction of general anesthesia and throughout the study.

\subsection{Statistical analyses}

We used preliminary data obtained from 10 patients to estimate sample size, and we further assumed that a change of 200 points in the SVR between the ephedrine and etilefrine groups at $0.5 \mathrm{~min}$ after injection would be clinically relevant. Our power analysis indicated that a 
minimum of 18 patients would be required to meet the criteria of $\beta=0.1$ and $\alpha=0.05$. We therefore enrolled 20 patients in each group to compensate for any potential dropouts. This analysis was conducted with GraphPad StatMate 2.00 (GraphPad Software, Inc., La Jolla, CA, USA).

Values are expressed as means \pm standard deviation (SD). Within-group differences of the recorded parameters were analysed by paired $t$-test with Bonferroni's correction to determine whether there were significant differences between the baseline values and the parameter values after injection. Betweengroup differences in these parameters were analysed by unpaired $t$-test. A $P$ value $<0.05$ was considered to indicate statistical significance. All analyses were conducted with GraphPad Prism 5.04 (GraphPad Software, Inc.).

\section{Results}

Details of patient recruitment and excluded participants are shown in Figure 1 (no patients showed tachycardia $[$ HR $>100])$. The 40 patients enrolled in this study were divided into the etilefrine group $(n=20)$ and the ephedrine group $(n=20)$. Patient characteristics were similar in both groups (Table 1).

After bolus injection of ephedrine, significant increases in the values of SAP, MAP, DAP, $\mathrm{HR}, \mathrm{P}_{\mathrm{ET}} \mathrm{CO}_{2}$, $\mathrm{CO}$, and SVI at the time points of 1 to $5 \mathrm{~min}$ and of SVV at the time point of $1 \mathrm{~min}$ were noted in comparison with the baseline values (Figures 2, 3). Significant decreases were noted in comparison with the baseline values at the time point of $1 \mathrm{~min}$ in SVR and at the time points of 2 to 5 min in SVV (Figure 3).

After bolus injection of etilefrine, significant increases occurred in SAP and SVI at the time points of 1 to $5 \mathrm{~min}$, in MAP and DAP at the time points of 2 to $5 \mathrm{~min}$, in $\mathrm{HR}$ at the time point of $1 \mathrm{~min}$, in $\mathrm{P}_{\mathrm{ET}} \mathrm{CO}_{2}$ at the time points of 1 to $4 \mathrm{~min}$, in $\mathrm{CO}$ at the time points of 0.5 to $5 \mathrm{~min}$, and in SVV at the time point of $0.5 \mathrm{~min}$ compared with the baseline values (Figures 2, 3). SVV at the time points of 2 to $5 \mathrm{~min}$ and SVR at the time points of 0.5 to $2 \mathrm{~min}$ also showed significant decreases compared with the baseline values (Figure 3).

$\mathrm{P}_{\mathrm{ET}} \mathrm{CO}_{2}$ at the time points of 1 to 2 min and $\mathrm{CO}$ at the time point of $1 \mathrm{~min}$ were higher in the etilefrine than ephedrine group (Figures 2, 3). SVR at the time points of 0.5 to $1 \mathrm{~min}$ was lower in the etilefrine than ephedrine group (Figure 3).

\section{Discussion}

Our results showed that in combined epidural and general anesthesia patients both drugs transiently decreased SVR after bolus IV injection and that etilefrine decreased SVR much more than ephedrine did, indicating that more vasodilation occurred after the injection of etilefrine than after that of ephedrine. Furthermore, we believe that $\mathrm{CO}$ in the patients

\section{Table 1 Patient characteristics}

\begin{tabular}{lcc}
\hline Items & $\begin{array}{c}\text { Ephedrine group } \\
(n=20)\end{array}$ & $\begin{array}{c}\text { Etilefrine group } \\
(n=20)\end{array}$ \\
\hline Age (years) & $54 \pm 16$ & $48 \pm 15$ \\
Sex (M/F) & $13 / 7$ & $16 / 4$ \\
Body weight $(\mathrm{kg})$ & $59 \pm 11$ & $61 \pm 12$ \\
Height $(\mathrm{cm})$ & $163 \pm 8$ & $168 \pm 10$ \\
Body surface area $\left(\mathrm{m}^{2}\right)$ & $1.63 \pm 0.18$ & $1.69 \pm 0.19$ \\
\hline
\end{tabular}

Values are presented as means \pm standard deviation or number.

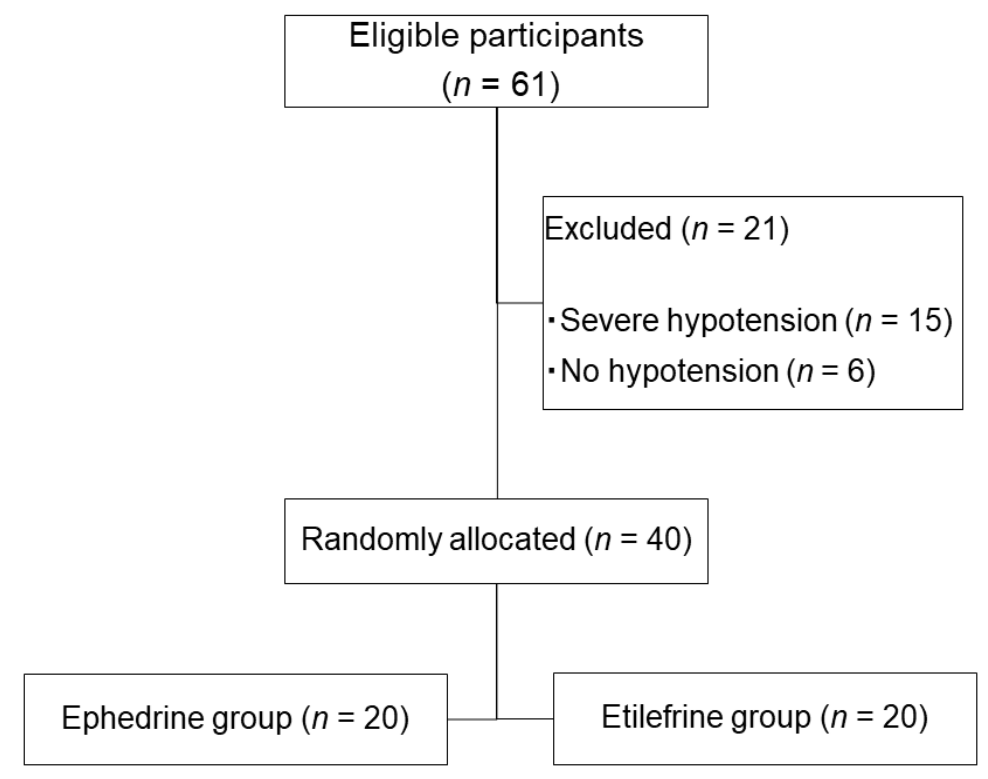

Figure 1. Selection of the study population. 

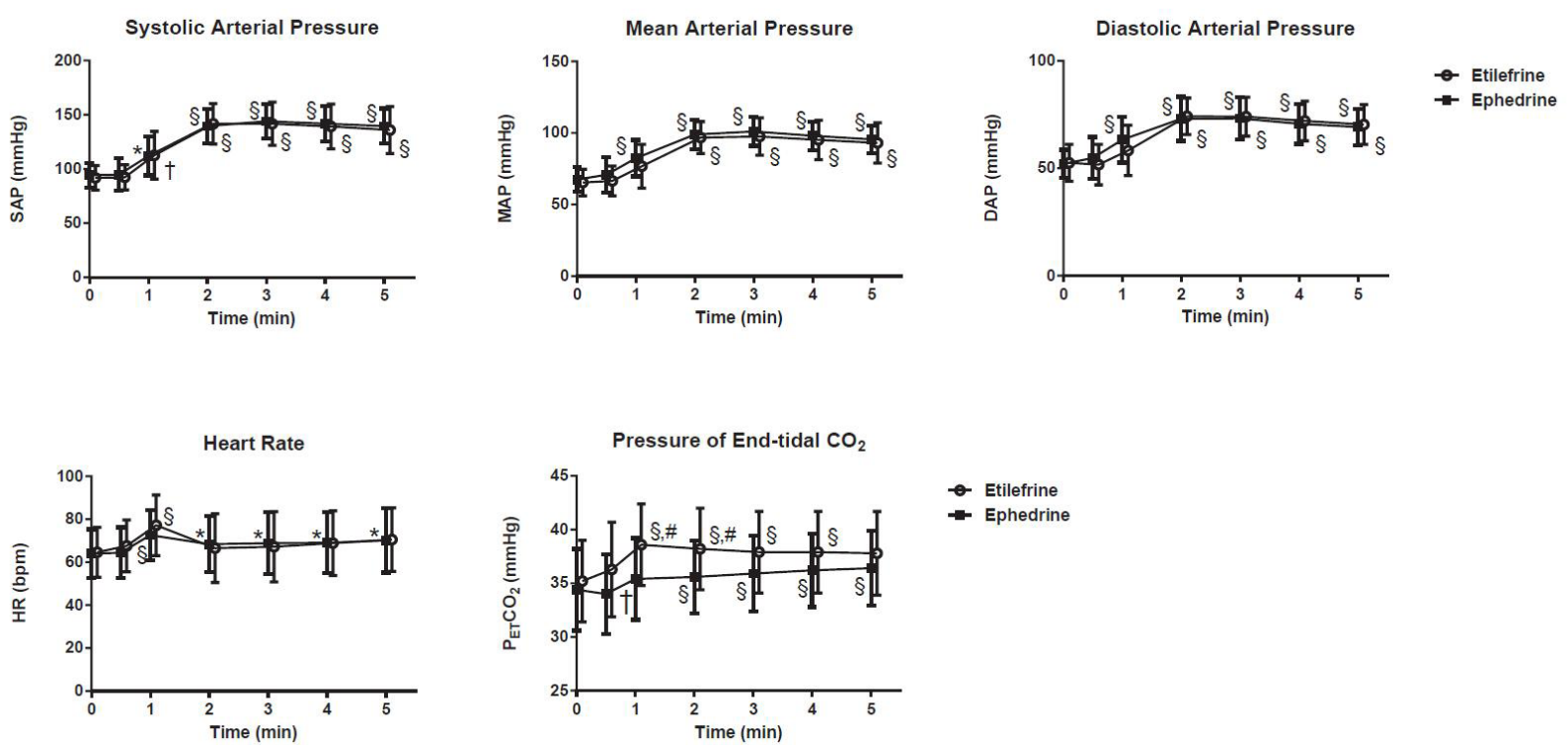

Figure 2. Sequential changes in systolic arterial pressure (SAP), mean arterial pressure (MAP), diastolic arterial pressure (DAP), heart rate (HR) and pressure of end-tidal $\mathrm{CO}_{2}\left(\mathrm{P}_{\mathrm{ET}} \mathrm{CO}_{2}\right)$ after IV bolus administration of etilefrine and ephedrine. Data are expressed as mean \pm standard deviation. ${ }^{*} P<0.05$ vs baseline; $\dagger P<0.01$ vs baseline; $¥ P<0.005$ vs baseline; $\$ P<0.001$ vs baseline; ${ }^{\sharp} P<0.05$ compared with the ephedrine group.
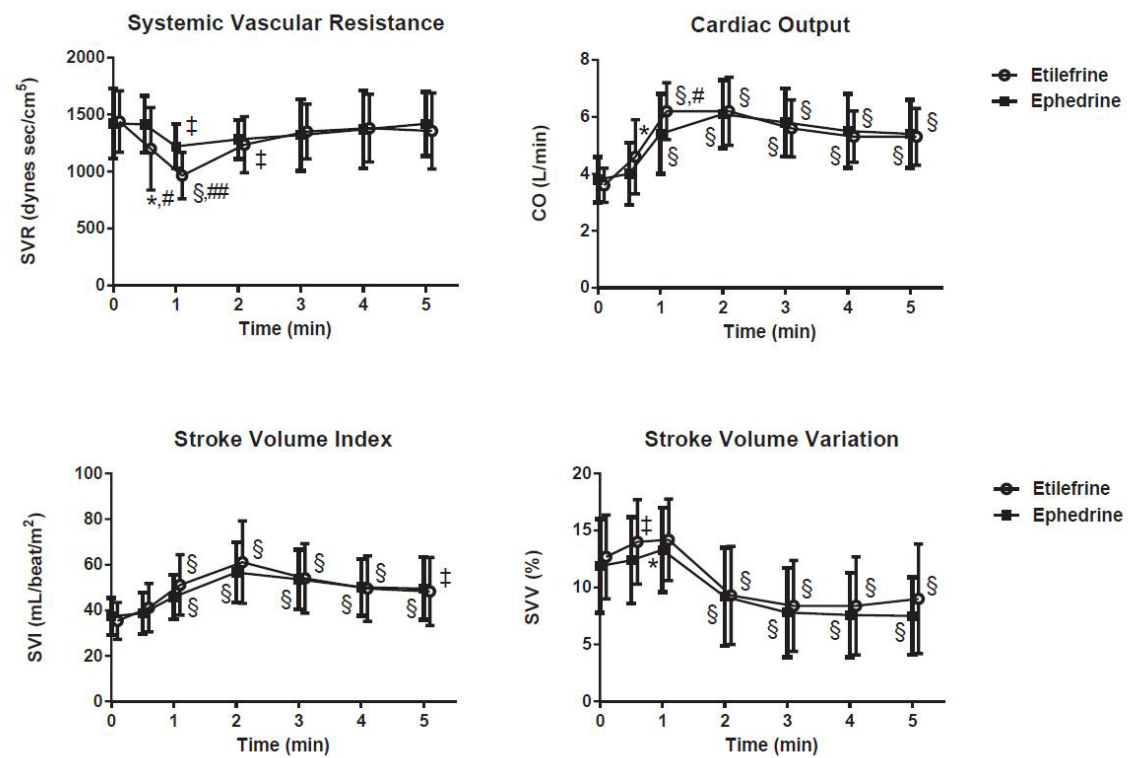

Figure 3. Sequential changes in systemic vascular resistance (SVR), cardiac output (CO), stroke volume index (SVI), and stroke volume variation (SVV) after IV bolus administration of etilefrine and ephedrine. Data are expressed as mean \pm standard deviation. ${ }^{*} P<0.05$ vs baseline; $\uparrow P<0.01$ vs baseline $₫ P<0.005$ vs baseline; $\$ P<0.001$ vs baseline; ${ }^{\sharp} P<0.05$ compared with the ephedrine group; ${ }^{\#} P<0.001$ compared with the ephedrine group.

receiving etilefrine was higher than that of the patients receiving ephedrine at that time because etilefrine induced more vasodilation than ephedrine did. This is new information on the action of these two drugs in combined epidural and general anesthesia patients.

Ephedrine, a commonly used vasopressor, primarily affects $\beta$-adrenergic receptors but also clearly affects $\alpha$-adrenergic receptors (4). Its cardiac effects result mainly from the $\beta$-mimetic component (4), whereas vasoconstriction in capacitance vessels and an increase in venous return are the results of its $\alpha$-adrenergic effects (4). As an indirect effect, ephedrine causes the release of norepinephrine from storage granules in the postganglionic nerve endings. It also directly effects adrenergic receptors by its nonselective predominantly indirect sympathomimetic effects at both $\alpha$ and $\beta$ receptors (ephedrine is similar in structure to amphetamine but with less blood-brain barrier penetration (10)), increases blood pressure as a result of venoconstriction, improves preload and $\mathrm{CO}$, and also has some chronotropic and inotropic effects.

Etilefrine is an effective vasopressor that stimulates 
$\alpha_{1}$ - and $\beta_{1}$-adrenoceptors $(4,17)$ with a much greater affinity for $\beta_{1}$ - rather than for $\beta_{2}$ adrenoreceptors (17) and also for $\beta_{1}$ - rather than $\alpha$-adrenoreceptors (17). Its molecular polarity is greater than that of ephedrine (4). In humans, previous studies showed that continuous and progressively increasing administration of IV etilefrine results in increased $\mathrm{HR}, \mathrm{CO}, \mathrm{CVP}$, and MAP and decreased peripheral vascular resistance (18) but there have been no studies on the cardiovascular effects of the bolus administration of etilefrine, and therefore we investigated these effects in this study.

Both drugs decreased SVR transiently after bolus IV injection, but etilefrine decreased SVR much more than ephedrine did, indicating that more vasodilation occurred after the injection of etilefrine than after ephedrine. The mechanism of vasodilation of these drugs possibly operates by activating endothelial production of nitric oxide (NO) through $\beta_{2}$ adrenoceptors (19-22); Dabisch et al. (21) demonstrated that the vascular response to ephedrine in rats was modulated by $\mathrm{NO}$ and that $\mathrm{NO}$ production in response to ephedrine may be secondary to $\beta_{2}$ receptor stimulation. We also surmise that both drugs initially act as a $\beta_{2}$-adrenoceptor agonist. Unfortunately, however, in this study, we could not explain why these drugs showed such action, and the mechanism also remains unclear. We can simply consider that both drugs initially act as a $\beta_{2}$-adrenoceptor agonist, and thereafter, these drugs affect not only $\beta_{1}$ but also $\alpha$-adrenergic receptors. In the future, measurement of the perfusion index (PI), a marker of peripheral perfusion, which is obtained by calculating the ratio of a pulsating signal to a nonpulsating signal would provide a hint to the mechanism (23-25) because PI depends on the vasomotor tone, which may affect the pulsatile absorption component in $\operatorname{man}(26,27)$.

Although we surmise that most anesthetists believe that both drugs simply increase blood pressure as the heart rate increases, we found that in the very short term (about 5 minutes), both drugs show characteristic hemodynamics. The present study is the first report to show that the IV bolus administration of both ephedrine and etilefrine decreases SVR (by inducing vasodilation) just after injection in combined epidural and general anesthesia patients, and no previous reports have measured SVR. Therefore, in patients with dehydration or poor cardiac function, for example, these drugs may be administered very cautiously because both drugs may first act as vasodilators, and thus, it is important to recognise the characteristics of these drugs. We believe that anesthetists should always consider using phenylephrine, which is a selective $\alpha_{1}$ agonist, instead of ephedrine or etilefrine, which can be vasodilators in patients undergoing combined epidural and general anesthesia.

Taivainen (3) gave elderly patients bupivacaine as spinal anesthesia, and if a $25 \%$ reduction in MAP from the preanesthetic reference value occurred, the patients were randomly chosen receive ephedrine 0.07 $\mathrm{mg} / \mathrm{kg}$ or etilefrine $0.03 \mathrm{mg} / \mathrm{kg}$ by IV bolus. He found ephedrine to be slightly more potent than etilefrine in restoring MAP and DAP. However, our results were different from those of Taivainen in regard to MAP and DAP because both MAP and DAP were comparable in our present study. We surmise that the reason for this difference relates to the differences in the dose ratio of ephedrine to etilefrine and also to the anesthesia method used. The results of SAP and HR in the Taivainen study (3) are comparable and similar to ours.

Values of $\mathrm{P}_{\mathrm{ET}} \mathrm{CO}_{2}$ at the time points of 1 to $2 \mathrm{~min}$ and $\mathrm{CO}$ at the time point of $1 \mathrm{~min}$ were higher in the etilefrine than ephedrine group (Figures 2,3). This result is related to the fact that changes in $\mathrm{CO}$ are qualitatively reflected by changes in $\mathrm{P}_{\mathrm{ET}} \mathrm{CO}_{2}$ during acute hemodynamic problems in anesthetized patients undergoing constant ventilation (28).

Several limitations are associated with our study. First, we compared the effects of ephedrine and etilefrine only under the combination of general anesthesia and epidural anesthesia and not separately with either epidural anesthesia or spinal anesthesia alone. Separate comparisons using these types of anesthesia should be investigated in the future. Furthermore, to investigate the early and true effects of these two vasoconstrictor drugs on SVR, we should use patients or volunteers without anesthesia. Second, we used the third-generation FloTrac/Vigileo ${ }^{\mathrm{TM}}$ (software ver. 03.06) to measure SVR. Recently, Suehiro et al. (29) reported that the third-generation FloTrac/Vigileo ${ }^{\mathrm{TM}}$ system can reliably measure $\mathrm{CO}$ only in states of normal peripheral resistance (SVR index: 1200-2500 dynes $\mathrm{sec} / \mathrm{cm}^{5} / \mathrm{m}^{2}$ ), and in their clinical review, they further reported the excellent reliability of $\mathrm{CO}$ measurement with the third-generation FloTrac/Vigileo ${ }^{\mathrm{TM}}$ in normal patients with SVR (> 700 dynes sec/ $\left.\mathrm{cm}^{5}\right)$ (30). Slagt et al. (31) recently reported that the third-generation system performed adequately in normotensive (surgery and general critical illness) and hypodynamic (cardiac and post-cardiac surgery) conditions but not during hyperdynamic conditions (liver surgery and sepsis). The SVR in our subjects was normal, and they were all in a normodynamic condition. Therefore, we believe that our data are clinically acceptable. However, further studies are needed in which the fourth-generation FloTrac/Vigileo ${ }^{\mathrm{TM}}$ system is used (32). Finally, as described above, we did not directly measure CVP via a central venous catheter but obtained the data for SVR by inputting a fixed CVP of $0 \mathrm{~mm} \mathrm{Hg}$ into the FloTrac/ Vigileo $^{\mathrm{TM}}$ system $(13,33)$. Taivainen (3) reported that although the administration of ephedrine and etilefrine tended to slightly increase the CVP, the values were basically unchanged, and we thought that the CVP value would have no bearing on the calculation of SVR by the FloTrac/Vigileo ${ }^{\mathrm{TM}}$ system. 
In conclusion, in combined epidural and general anesthesia patients, the administration of both ephedrine and etilefrine transiently decreased SVR after IV bolus injection, but etilefrine decreased SVR much more than ephedrine did, indicating that more vasodilation occurred after the injection of etilefrine than after ephedrine. In patients with dehydration or severe hypotension, caution may be needed when using these two drugs, and it is thus important to recognize the individual characteristics of each drug.

Note: This work was conducted in the Department of Anesthesiology, International University of Health and Welfare Shioya Hospital, Tochigi, Japan.

\section{References}

1. Desjardins G, Vezina DP, Johnson KB, Cahalan MK. Perioperative Echocardiography. In: Miller's anesthesia (Miller RD, ed.). Elsevier Saunders Philadelphia, PA, 2015; pp. 1419-1420.

2. Veering BT, Cousins MJ. Epidural Neural Blockade. In: Cousins \& Bridenbaugh's neural blockade in clinical anesthesia and management of pain (Cousins MJ, Carr DB, Horlocker TT, Bridenbaugh PO, eds.). Lippincott Williams \& Wilkins, a Wolters Kluwer business, Philadelphia, PA, 2009; pp. 241-295.

3. Taivainen T. Comparison of ephedrine and etilefrine for the treatment of arterial hypotension during spinal anaesthesia in elderly patients. Acta Anaesthesiol Scand. 1991; 35:164-169.

4. Räsänen J, Alahuhta S, Kangas-Saarela T, Jouppila R, Jouppila $\mathrm{P}$. The effects of ephedrine and etilefrine on uterine and fetal blood flow and on fetal myocardial function during spinal anaesthesia for caesarean section. Int J Obstet Anesth. 1991; 1:3-8.

5. Eldor J. Ephedrine in the initial treatment of haemorrhagic shock. Med Hypotheses. 1991; 35:250252.

6. Wright PM, Fee JP. Cardiovascular support during combined extradural and general anaesthesia. Br J Anaesth. 1992; 68:585-589.

7. Goertz AW, Seeling W, Heinrich H, Lindner KH, Rockemann MG, Georgieff M. Effect of phenylephrine bolus administration on left ventricular function during high thoracic and lumbar epidural anesthesia combined with general anesthesia. Anesth Analg. 1993; 76:541545.

8. Belzarena SD. Ephedrine and etilefrine as vasopressor to correct maternal arterial hypotension during elective cesarean section under spinal anesthesia. Comparative study. Rev Bras Anestesiol. 2006; 56:223-229.

9. Van Haren RM, Thorson CM, Valle EJ, Guarch GA, Jouria JM, Busko AM, Namias N, Livingstone AS, Proctor KG. Vasopressor use during emergency trauma surgery. Am Surg. 2014; 80:472-478.

10. Wajima Z, Shitara T, Ishikawa G, Kaneko K, Inoue T, Ogawa R. Analgesia after upper abdominal surgery using extradural administration of a fixed dose of buprenorphine in combination with lignocaine given at two infusion rates: A comparative study. Acta Anaesthesiol Scand. 1997; 41:1061-1065.
11. Wajima Z, Shitara T, Ishikawa G, Inoue T, Ogawa R. Analgesia after upper abdominal surgery with extradural buprenorphine with lidocaine. Can J Anaesth. 1998; 45:28-33.

12. Wajima $Z$, Shiga $T$, Imanaga $K$, Inoue $T$. Does intravenous landiolol, a $\beta_{1}$-adrenergic blocker, affect stroke volume variation? J Anesth. 2013; 27:890-894.

13. Wajima Z, Shiga T, Imanaga K. Pneumoperitoneum affects stroke volume variation in humans. J Anesth. 2015; 29:508-514.

14. Strümper D, Gogarten W, Durieux ME, Hartleb K, Van Aken H, Marcus MA. Effects of cafedrine/theodrenaline, etilefrine and ephedrine on uterine blood flow during epidural-induced hypotension in pregnant sheep. Fetal Diagn Ther. 2005; 20:377-382.

15. Biais M, Vidil L, Sarrabay P, Cottenceau V, Revel P, Sztark F. Changes in stroke volume induced by passive leg raising in spontaneously breathing patients: Comparison between echocardiography and Vigileo/ FloTrac device. Crit Care. 2009; 13:R195.

16. Portnoy D. Ephedrine. In: Essence of Anesthesia Practice (Fleisher LA, Roizen MF, eds.). Elsevier Saunders Philadelphia, PA, 2011; pp. 604.

17. Offermeier J, Dreyer AC. A comparison of the effects of noradrenaline, adrenaline and some phenylephrine derivatives on alpha-, beta ${ }_{1}$ - and beta $\mathrm{b}_{2}$ - adrenergic receptors. S Afr Med J. 1971; 45:265-267.

18. Coleman AJ, Leary WP, Asmal AC. The cardiovascular effects of etilefrine. Eur J Clin Pharmacol. 1975; 8:41-45.

19. Gray DW, Marshall I. Novel signal transduction pathway mediating endothelium-dependent $\beta$-adrenoceptor vasorelaxation in rat thoracic aorta. Br J Pharmacol. 1992; 107:684-690.

20. Chang HY. Role of nitric oxide in vasodilator response induced by salbutamol in rat diaphragmatic microcirculation. Am J Physiol. 1997; 272:H2173-2179.

21. Dabisch PA, Liles JT, Kadowitz PJ. Effect of inhibition of nitric oxide synthase on the vasopressor response to ephedrine. Can J Physiol Pharmacol. 2003; 81:966-971.

22. Dessy C, Moniotte S, Ghisdal P, Havaux X, Noirhomme $\mathrm{P}$, Balligand JL. Endothelial $\beta_{3}$-adrenoceptors mediate vasorelaxation of human coronary microarteries through nitric oxide and endothelium-dependent hyperpolarization. Circulation. 2004; 110:948-954.

23. Ginosar Y, Weiniger CF, Kurz V, Babchenko A, Nitzan M, Davidson E. Sympathectomy-mediated vasodilatation: A randomized concentration ranging study of epidural bupivacaine. Can J Anaesth. 2009; 56:213-221.

24. Ginosar Y, Weiniger CF, Meroz Y, Kurz V, BdolahAbram T, Babchenko A, Nitzan M, Davidson EM. Pulse oximeter perfusion index as an early indicator of sympathectomy after epidural anesthesia. Acta Anaesthesiol Scand. 2009; 53:1018-1026.

25. Wajima Z, Shiga T, Imanaga K. Does pneumoperitoneum affect perfusion index and pleth variability index in patients receiving combined epidural and general anesthesia? Biosci Trends. 2018; 11:667-674.

26. Lima AP, Beelen P, Bakker J. Use of a peripheral perfusion index derived from the pulse oximetry signal as a noninvasive indicator of perfusion. Crit Care Med. 2002; 30:1210-1213.

27. Lima A, Bakker J. Noninvasive monitoring of peripheral perfusion. Intensive Care Med. 2005; 31:1316-1326.

28. Shibutani K, Muraoka M, Shirasaki S, Kubal K, Sanchala VT, Gupte P. Do changes in end-tidal $\mathrm{PCO}_{2}$ 
quantitatively reflect changes in cardiac output? Anesth Analg. 1994; 79:829-833.

29. Suehiro K, Tanaka K, Funao T, Matsuura T, Mori T, Nishikawa K. Systemic vascular resistance has an impact on the reliability of the Vigileo-FloTrac system in measuring cardiac output and tracking cardiac output changes. Br J Anaesth. 2013; 111:170-177.

30. Suehiro K, Tanaka K, Matsuura T, Funao T, Yamada T, Mori T, Nishikawa K. The Vigileo-FloTrac system: Arterial waveform analysis for measuring cardiac output and predicting fluid responsiveness: A clinical review. J Cardiothorac Vasc Anesth. 2014; 28:1361-1374.

31. Slagt C, Malagon I, Groeneveld AB. Systematic review of uncalibrated arterial pressure waveform analysis to determine cardiac output and stroke volume variation. $\mathrm{Br}$ J Anaesth. 2014; 112:626-637.

32. Suehiro K, Tanaka K, Mikawa M, Uchihara Y, Matsuyama T, Matsuura T, Funao T, Yamada T, Mori T, Nishikawa K. Improved Performance of the FourthGeneration FloTrac/Vigileo System for Tracking Cardiac Output Changes. J Cardiothorac Vasc Anesth. 2015; 29:656-662.

33. Wajima Z, Shiga T, Imanaga K, Inoue T. Vigilance of hemodynamic changes immediately after transferring patients is crucial. J Anesth. 2013; 27:521-527.

(Received April 18, 2018; Revised July 7, 2018; Accepted July 29, 2018) 